\title{
O DESAFIO DO ENSINO POR COMPETÊNCIAS NA EDUCAÇÃO PROFISSIONAL EM ENFERMAGEM
}

\author{
Isabel Cristina Adão, Ernani Coimbra de Oliveira \\ Instituto Federal de educação, Ciência e Tecnologia do Sudeste de Minas Gerais \\ São Carlos, Minas Gerais \\ E-mail: isabel.schiavon@ifsudestemg.edu.br, ritabortolettosantos@gmail.com
}

\section{Anadias Trajano Camargos}

Universidade Federal de Minas Gerais

Belo Horizonte, Minas Gerais

E-mail: anadias@enf.ufmg.br

\section{Ana Cristina Pederiva \\ Universidade Federal de São João del-Rei \\ São João del-Rei, Minas Gerais \\ E-mail: anacristina_pederiva@yahoo.com.br}

Resumo: Diversos autores apontam o modelo por competências como o ideal para o ensino profissional. O objetivo do trabalho foi identificar estratégias dentre as contribuições das pesquisas produzidas pela Enfermagem brasileira acerca da temática currículo por competências, tomando por base a produção científica nacional. Trata-se de um estudo exploratório e descritivo com abordagem qualitativa. Optou-se por utilizar como referencial metodológico a revisão integrativa. Nos desafios apontados, sobressaiu-se a necessidade de mudança e a figura do docente aparece como figura central nessa mudança.

Palavras-chave: enfermagem, competências profissionais, educação profissionalizante.

\section{THE CHALLENGE OF TEACHING BY COMPETENCIES IN PROFESSIONAL EDUCATION IN NURSING}

Abstract: Several authors point to the competency model as the ideal for vocational education. The study objective was to highlight strategies among the contributions of the research produced by Brazilian Nursing concerning the thematic curriculum by competencies, based on the national scientific production. This is an exploratory and descriptive study with qualitative approach. We chose to use as its methodological integrative review. In the challenges mentioned, stood out the need for change and the figure of the teacher appears as a central figure in this change.

Keywords: nursing, professional competencies, professional education.

Recebido em 04/11/2015. Publicado em 30/09/2016. 


\section{INTRODUÇÃO}

As configurações atuais da sociedade, marcada por avanços tecnológicos e rápidas transformações, exigem profissionais aptos a lidar com o novo, com o inesperado, com as incertezas. É necessário que o profissional seja flexível e esteja disposto a buscar e aceitar diferentes opções, em um constante trabalho de atualização, atendendo a novas demandas e buscando novas aprendizagens e possibilidades (PEREIRA, 2005). Nesse viés, é possível afirmar que o modelo tradicional de ensino, ainda vigente na grande maioria das instituições, não corresponde às necessidades do contexto atual.

O modelo tradicional de ensino baseia-se na "transmissão de conhecimentos", tendo como principais metodologias a exposição verbal da matéria e exercícios de memorização e fixação de conteúdo, o que é feito predominantemente por meio do material didático (OLIVEIRA, 2006). O aluno "recebe" todo o conhecimento pronto, e não é incentivado a construir nem problematizar a aprendizagem. Corroborando a mesma ideia acrescenta-se que este modelo de ensino também pode ser denominado como "educação bancária", uma vez que visa a mera transmissão de conteúdos e não considera a realidade ou os conhecimentos prévios que do educando (FREIRE, 1987). Portanto, este torna-se um agente passivo do processo de ensino/aprendizagem.

Outro aspecto a ser ressaltado no modelo de ensino tradicional é a ausência, em grande parte dos casos, de interação aluno/aluno e aluno/professor. Nesse contexto, o professor é considerado o único detentor do conhecimento, do saber, e responsável por todo o processo de aprendizagem. Portanto, é como se as interações não fossem necessárias (NIQUINI, 1999). Neste sentido, há demasiada valorização do conteúdo e não há oportunidades para que este possa ser relacionado à realidade dos educandos. Além disso, há uma excessiva imposição de disciplina e a rotina é inflexível. 
Em um contexto de rápidas mudanças tecnológicas e de novas lógicas de mercado, o sistema educativo é confrontado com a necessidade de fornecer novas oportunidades educacionais para que os educandos sejam capazes de lidar com as especificidades tanto do mercado de trabalho quanto da sociedade, e possam, ao mesmo tempo, melhorar sua qualidade de vida (VIDAL, 2002). Sendo assim, é possível afirmar que o modelo tradicional de ensino não atende às novas necessidades da sociedade, uma vez que não contribui para a formação de sujeitos criativos, autônomos, participativos, solidários e interativos, condições fundamentais para lidar com situações e problemas corriqueiros, inerentes ao novo milênio.

Wittaczik (2007) destaca que diante das novas necessidades da sociedade, o Ministério da Educação e Cultura propôs o ensino por competências. Este assume uma metodologia de ensino voltada à formar profissionais não apenas com competência técnica, mas também crítica e criativa, política e ética. O ensino, por sua vez, é centrado no sujeito, com propostas de aprendizagem em atividades, projetos e exercícios relacionados às competências pretendidas. Tais metodologias têm a finalidade de desenvolver nos educandos capacidades de diagnóstico e solução de problemas e aptidões para tomar decisões, trabalhar em equipe, enfrentar situações em constantes mudanças e intervir no trabalho para melhoria da qualidade dos processos, produtos e serviços.

De acordo com Ricardo (2010), a expansão dos currículos para competências gerais associadas a saberes específicos busca, na maioria das vezes, minimizar conflitos entre os defensores dos saberes disciplinares e os adeptos da cultura generalista. Para evitar falsas abordagens por competências, um programa estruturado nessa perspectiva deve determinar o grau de abrangência das competências que pretende construir, ao mesmo tempo sem explicitar todas as competências e conteúdos de forma padronizada, tirando qualquer autonomia do professor. Perrenoud (2002), aponta a necessidade de considerar os aspectos aproximativos dos recursos mobilizados em determinada situação-problema como uma característica da própria lógica da ação. 
Isso, de certa forma, põe a formação por competência em oposição à educação bancária, denunciada por Paulo Freire, na qual o professor deposita seus conhecimentos no aluno sem considerar sua realidade e seus conhecimentos prévios. A dimensão desafiadora do ensino por competências permite que o educador se acostume a trabalhar com problemas e possa, então, desenvolver o potencial criativo e inovador de seus educandos. Nessa direção, Mandon (1990) apud Stroobants (1997, p.142) ressalta que o ensino de competências é voltado a uma mobilização de conhecimentos e qualidades para a solução de problemas, evidenciando que a competência revela-se de modo contextualizado. As competências mobilizadas seriam expressas através do trio: saber, saber fazer e saber ser.

A urgência pelo entendimento do modelo de competências está relacionada às novas compreensões de trabalho, e ainda, implicitamente, às concepções do mundo empresarial, estabelecidas na flexibilidade e na exigência de sujeitos ágeis, comprometidos, autônomos, responsáveis, disponíveis, comunicativos e polivalentes. Hoje, na educação, não devemos estar somente comprometidos com a diversidade de conteúdos ou com o aprendizado das diferentes linguagens, mas também com a formação de competências sociais, como coloca Mello (1993, p. 30):

[...] como liderança, iniciativa, capacidade de tomar decisões, autonomia de trabalho, habilidade de comunicação, constituem novos desafios Educacionais. Em contraposição ao acúmulo de informações segmentadas e superficiais, torna-se mais importante dominar em profundidade as básicas e as formas de acesso à informação, desenvolvendo a capacidade de reunir e organizar aquelas que são relevantes.

Nas Diretrizes Curriculares Nacionais (Brasil, 2002, p. 108) dos cursos superiores de tecnologia, entende-se por competência profissional "a capacidade de articular, mobilizar e colocar em ação valores, conhecimentos e habilidades necessários para o desempenho eficiente e eficaz de atividades requeridas pela natureza do trabalho". Nesta noção de competência o conhecimento é 
estabelecido como saber. A habilidade é o saber fazer vinculado à prática do trabalho. E o saber ser inclui atitudes relacionadas ao julgamento da ação.

As bases teórico-metodológicas dos sistemas de competência profissional são integralizadas por três subsistemas com características conceituadas conforme a matriz de investigação dos processos de trabalho: normalização das competências, formação por competências, avaliação e certificação de competências. É importante a visão de Ramos ao destacar que

A investigação das competências tem por objetivo garantir a evidência das competências requisitadas pelos empregos, possibilitando a definição e a sistematização de um perfil profissional. Elaboram-se, então, as normas de competência mediante a confrontação do perfil com as ocupações ou situações típicas de trabalho, deduzindo-se os desempenhos satisfatórios. A partir de então, o Estado e as próprias organizações empresariais podem promover processos de formação para orientar a aquisição dessas competências, avaliá-las e certificá-las, tomando decisões com base nesses dados ( RAMOS, 2001 p. 80-81).

Neste contexto histórico da educação é possível perceber que a noção de competência se localiza como uma nova mediadora, substituída pela acumulação flexível do capital. Nesta situação, a competência aparece como algo definido que mostra, mas não revela, a essência produzida pelas relações sociais de produção (VAZ, 2009).

Lopes (2002) aponta que a estreita relação entre o mundo produtivo e a educação, visa preparar o sujeito para viver em um mundo cada vez mais competitivo, onde o desenvolvimento da "empregabilidade" torna-se vital. Sendo assim, a educação não mais está voltada à formação de sujeitos para a ocupação de postos específicos no mercado de trabalho, com base em 
qualificações profissionais específicas. Diferentemente, articula-se o desenvolvimento e o aprimoramento de competências e habilidades para o desempenho e a atuação profissional em um mundo onde o trabalho está em constante mudança e onde não há garantia de emprego.

Ressalta-se que a partir disso, a qualificação profissional não se resume às atividades menos complexas, necessárias no contexto do paradigma taylorista-fordista, mas assume um caráter mais abstrato, com habilidades e competências superiores necessárias às tecnologias que sustentam as novas formas de produção do contexto pós-fordista. Trata-se de um processo que acaba por se constituir como uma tentativa de responsabilizar os indivíduos pelo possível fracasso de sua inserção nessa sociedade em constante mudança.

No entanto, de acordo com Rehem (2005), com os imperativos dos tempos atuais desafiando os atores da educação profissional, torna-se necessário pensar um currículo que considere que os futuros profissionais atuarão em um mercado volátil, no qual as regras mudam no decorrer do jogo e a tecnologia se transforma a cada dia. Dessa forma, o ensino por competências ainda é o mais adequado para a sociedade atual.

Adquirir conhecimentos, apenas, não é suficiente para a atuação profissional. Para além dos conhecimentos, o sujeito deverá desenvolver habilidades, valores, atitudes e a capacidade de mobilizar, articular e integrar os conhecimentos na prática da vida profissional. Morin (2001) aponta para a necessidade de desenvolver uma cabeça bem feita em oposição à cabeça bem cheia, entendendo que conhecimentos são rapidamente superados e defasados, e capacidades, no entanto, são mais duradouras e permitem a aquisição permanente de novos conhecimentos: "uma cabeça bem feita" significa que ao invés de acumular o saber, é mais importante dispor de uma aptidão geral para colocar e tratar os problemas, além de possuir princípios organizadores que permitam ligar os saberes. 
Sendo assim, a educação não deve bastar-se em um mero saber, mas sim em uma cultura, que permita compreender a condição de complexidade dos problemas cotidianos, ajude a viver de maneira mais equilibrada e, ao mesmo tempo, favoreça um modo de pensar aberto e livre. Morin aponta para a gravidade da fragmentação dos saberes, que compromete a aprendizagem:

Há inadequação cada vez mais ampla, profunda e grave entre os saberes separados, fragmentados, compartimentados entre disciplinas, e, por outro lado, realidades ou problemas cada vez mais polidisciplinares, transversais, multidimensionais, transnacionais, globais, planetários. Em tal situação, tornam-se invisíveis os conjuntos complexos, as interações, as retroações entre as partes e o todo, as entidades multidimensionais, os problemas essenciais (MORIN, 2001, p.130).

A aprendizagem de uma profissão está diretamente relacionada ao complexo, e os saberes dissociados e descontextualizados, inerentes ao ensino tradicional, contribuem para uma visão fragmentada e dissociada da realidade. Lastreando-se nessas ideias, a educação profissional comprometida em formar um profissional contemporâneo, que esteja apto ao trabalho e continue aprendendo por toda a vida, entenderá que o "conhecimento pertinente é capaz de situar qualquer informação em seu contexto e, se possível, no conjunto em que está inscrita" (MORIN, 2001, p.15). O conhecimento, então, avança pela capacidade de contextualizar, inter-relacionar, englobar e integrar.

Os conteúdos da educação profissional contemporânea, portanto, devem ser comprometidos em fazer com que o educando aprenda a trabalhar no complexo mercado das economias globalizadas. E este aprendizado não pode resumir-se a uma lista de conhecimentos estruturados em disciplinas fragmentadas, transmitidos pelos professores numa concepção de educação bancária e tradicional de ensino. 
Nenhuma lista de tarefas, e nem mesmo um retrato da complexidade de um processo de trabalho, traduz tudo o que pode acontecer no enfrentamento real do sujeito com a materialidade concreta do trabalho. E o conceito de competência surge para dar destaque à imprevisibilidade dos processos. Isto perde totalmente o sentido se considerarmos que o trabalho se orienta somente por normas prescritas. Se assim fosse, pouco precisaríamos pensar a respeito de conhecimentos, valores e mediações próprias da relação do homem com o mundo material e social. Esse ponto ainda parece pouco debatido no âmbito das políticas educacionais, implantadas com base na compreensão de que competência diz respeito às mediações presentes na relação entre o processo de trabalho, o ensinar e o aprender (RAMOS, 2001).

O perfil do profissional que deseja inserir-se no atual mercado de trabalho, então, deve abarcar diversas habilidades. Estas relacionadas à criatividade, sociabilidade, disciplina, empreendedorismo, iniciativa, autonomia, rapidez de raciocínio, ética, solidariedade, atualização permanente, conhecimentos científicos e técnicos aprofundados, conteúdos relacionados ao ensino de técnicas, além de procedimentos sobre o como fazer.

A inter , a multi e a transdisciplinaridade enfatizam o pensamento sistêmico, concebendo a informação como matéria-prima a ser dominada e integrada pelo conhecimento. Ademais, entendem que o conhecimento deve ser permanentemente revisitado e revisado pelo pensamento, e que o pensamento é, mais do que nunca, o capital mais precioso para o indivíduo e a sociedade (MORIN, 2001). A partir disso, torna-se possível atuar na formação de sujeitos ativos, críticos, reflexivos e conscientes do seu papel enquanto agentes transformadores da sociedade (FREIRE, 2004).

A experiência de diversos autores mostra que a área da Enfermagem tem como compromisso produzir cuidados integrais de saúde voltados ao atendimento das necessidades de saúde do 
paciente e da comunidade nas diferentes fases do ciclo vital, tanto no âmbito dos serviços públicos de saúde, quanto nos serviços privados. Soma-se a isso, o compromisso de integrar-se a outros setores econômicos e sociais, relevantes para as condições de saúde individual e coletiva, que poderão interferir no nível da saúde comunitária e na organização dos serviços. Destaca-se, ainda, a necessidade de que o profissional de enfermagem possua uma gama de conhecimentos, fundamentados em saber, ser, sentir e fazer, que lhe permita prestar cuidados efetivos ao cliente, além de interagir com demais profissionais da saúde, na busca de um atendimento integral.

Deve-se atentar para o fato de que o homem tem um potencial geral em maior ou menor extensão. Dá-se a este conceito o nome de múltiplas inteligências. A partir disso cabe-nos buscar novos paradigmas, uma vez que nossas formas de pensar a cognição humana encontram-se ultrapassadas e injustas, já que se baseiam apenas em padrões lógicos e linguísticos, e os modelos educacionais em saúde seguem essa forma, tornando-se ineficientes.

A concretização desse perfil profissional dar-se-á mediante uma formação que proporcione aos futuros profissionais a capacidade de se verem e se conhecerem, ou seja, uma nova elaboração baseada na consciência crítica e nas capacidades de encontrar e associar informações, trabalhar em grupo, comunicar-se com desenvoltura, saber lidar com imprevistos e adaptar-se rapidamente às mudanças. Diante da complexidade das políticas de saúde brasileiras, do modelo assistencial proposto pelo Sistema Único de Saúde (SUS) e dos avanços científicos e tecnológicos, a Enfermagem vive um momento em que mudanças são propostas, centrando as ações em um modelo planejado a partir das necessidades de saúde da população, garantindo e viabilizando o direito de todos a um serviço capaz de suprir essas necessidades de forma integral.

Em meio a toda essa discussão surge a nova proposta do Conselho Estadual de Educação do Estado de São Paulo. Esta, levando em conta as transformações em andamento e as tendências do futuro, propõe antigas reivindicações como: descentralização, planejamento pedagógico realizado 
pela unidade escolar e currículo flexível, transferindo às escolas essas responsabilidades para que se diminua a distância entre quem planeja e quem executa, legado de 20 anos de autoritarismo.

Assim, o maior desafio das escolas formadoras de profissionais de Enfermagem, em especial os cursos de Formação Técnica de Nível Médio, é contribuir para a concretização desse novo modelo, a partir da criação e operacionalização de novos fundamentos para a prática da Enfermagem. Uma prática, então, voltada à promoção da saúde e prevenção de doenças, reconhecendo no paciente/cliente um participante de toda a ação assistencial. É importante, também, considerar a possibilidade da atuação desses profissionais no espaço extra hospitalar de assistência à saúde, uma tendência mundial, que requer do profissional o preparo adequado para o exercício dessa função.

As grades curriculares e planos de curso devem contemplar esse conjunto de necessidades, mantendo coerência com o mercado de trabalho e o atual cenário da saúde no país. Em Sessão Plenária realizada em 05/07/2000, o Conselho Estadual de Educação de São Paulo lançou as diretrizes para a implementação da Educação Profissional de nível Técnico no sistema de ensino do Estado de São Paulo, criando novas exigências aos cursos de formação. A principal delas é

[...] a do desenvolvimento de competências profissionais que permitam ao cidadão-trabalhador enfrentar e responder a desafios profissionais esperados e inesperados, previsíveis e imprevisíveis, rotineiros e inusitados, com criatividade, autonomia, ética e efetividade (CEE, 2000).

A educação assim concebida necessita que conhecimentos, habilidades e valores sejam colocados em ação, para que as atividades possam ser desenvolvidas com eficácia. Para tanto, é necessário que o enfoque tradicional da educação profissional seja mudado, abandonando o modelo centrado no treinamento operacional e na preparação para a execução de tarefas. Tendo em vista esse novo propósito, o Conselho aprovou, de acordo com as orientações básicas da Lei de 
Diretrizes e Bases da Educação (LDB), uma descentralização na organização e planejamento dos cursos de nível técnico (BRASIL, 2010).

Flexibilidade, interdisciplinaridade e contextualização conformam um princípio diretamente ligado ao grau de autonomia conquistado pela escola na concepção, elaboração, execução e avaliação do seu projeto pedagógico, fruto e instrumento de trabalho do conjunto dos seus agentes educacionais, especialmente os docentes. Esse princípio reflete na construção dos currículos em diferentes perspectivas, o que abre um horizonte de liberdade e, ainda, de maior responsabilidade para a escola. Ao elaborar o seu plano de curso, cabe à escola construir o currículo, estruturado em função do perfil profissional de conclusão desejado, conciliando as aspirações e demandas dos trabalhadores, dos empregadores e da sociedade. Essa flexibilidade permite à escola obter maior agilidade na proposição, atualização e incorporação de inovações e nas correções de rumos e adaptações às mudanças, o que implica numa organização do trabalho pedagógico de forma interdisciplinar ou, até mesmo, transdisciplinar.

Este trabalho pretende ser uma contribuição ao desenvolvimento das escolas de ensino profissional, oferecendo subsídio para a elaboração e avaliação de suas novas grades curriculares e projetos pedagógicos. Coloca-se como objetivo, para tanto, discutir estratégias dentre as contribuições das pesquisas produzidas pela Enfermagem brasileira acerca da temática currículo por competências. Busca-se a compreensão sobre o caminho a percorrer na implementação desse novo modelo, a partir da seguinte questão norteadora: quais são os desafios da transposição do modelo tradicional de ensino pelo modelo por competências na formação do técnico de enfermagem?.

\section{PROCEDIMENTOS METODOLÓGICOS}

Nesta pesquisa optou-se pelo método de revisão integrativa da literatura e as seguintes fases foram percorridas: identificação do tema, amostragem ou busca na literatura, categorização dos estudos, avaliação dos estudos, interpretação dos resultados e, por fim, síntese do conhecimento evidenciado nos artigos analisados ou apresentação da revisão integrativa. 


\subsection{Método e etapas}

Segundo Souza, Silva e Carvalho (2010), a revisão integrativa é "[...] um método que proporciona a síntese de conhecimento e a incorporação da aplicabilidade de resultados de estudos significativos na prática".

A sua realização culmina na possibilidade de oferecer subsídios para a implementação de modificações que promovam a qualidade das condutas assistenciais e formativas de enfermagem por meio de modelos de pesquisa.

A pergunta norteadora desta revisão integrativa consistiu em: quais são os desafios da transposição do modelo tradicional de ensino pelo modelo por competências na formação do técnico de enfermagem?

\subsection{Critérios de inclusão}

A amostra foi definida pelas publicações que atenderam aos critérios de inclusão préestabelecidos:

- Publicações no período de 2001 a 2011(10 anos).

- Apenas publicações com texto completo.

- Publicações que contemplavam ao mesmo tempo o assunto currículo por competências, ensino profissional e Enfermagem.

\subsection{População e amostra}

O levantamento bibliográfico baseou-se nas fontes relevantes à enfermagem e ao tema e aconteceu no período compreendido entre os meses de Setembro e Novembro/2014. Assim sendo, foram definidas as seguintes bases de dados:

$\checkmark$ Portal Scientific Electronic Library Online (SciELo): biblioteca eletrônica virtual que reúne uma coleção selecionada de revistas acadêmicas brasileiras e internacionais.

$\checkmark$ Portal Biblioteca Regional de Medicina (BIREME): através da Biblioteca Virtual em Saúde (BVS), organiza e disponibiliza a produção acadêmica literária, em vários idiomas, para os países da América Latina e Caribe. 
$\checkmark$ Base de dados do Instituto Brasileiro de Informação em Ciência e Tecnologia (IBICT): maior base de dados brasileira, reunindo publicações de grande parte das universidades brasileiras.

$\checkmark$ Base de dados Literatura Latino Americana e do Caribe em Ciências da Saúde (LILACS): considerada o mais importante e abrangente índice da literatura científica e técnica da América Latina e Caribe.

Os descritores utilizados foram: competências profissionais, enfermagem, educação profissionalizante.

Os descritores foram definidos a partir de busca nos Descritores em Ciências da Saúde (DECS) da Biblioteca Regional de Medicina (BIREME). E foram utilizados para localizar os trabalhos pelos seus assuntos. A partir daí houve a leitura do resumo disponível para confirmar a inclusão da bibliografia na pesquisa.

$\mathrm{Na}$ base de dados LILACS encontramos seis artigos, no IBICT encontramos oito documentos entre teses e dissertações. Na base de dados SciELO encontramos dois artigos que já haviam sido encontrados pelo LILACS, e sendo assim, foram excluídos.

\subsection{Variáveis do estudo}

- $\quad$ Autores: profissão, área de atuação, titulação.

- $\quad$ Documentos: periódico, delineamento, biblioteca de origem, tipo de publicação.

- Variável de interesse: relacionada à questão do estudo.

\subsection{Instrumento de coleta de dados}

A coleta de dados do estudo foi feita através de um instrumento confeccionado pela própria pesquisadora, submetendo-o, primeiramente, a um pré-teste a fim de adequá-lo aos propósitos da pesquisa. O instrumento elaborado contempla os itens: identificação do artigo original, características metodológicas do estudo, avaliação do rigor metodológico, intervenções estudadas e resultados encontrados.

A análise dos dados extraídos foi realizada de acordo com seus conteúdos, de forma descritiva, a fim de possibilitar à pesquisadora a avaliação da qualidade dos resultados encontrados, buscando 
identificar o nível de evidência disponível na literatura sobre o tema investigado, a possibilidade de fornecer subsídios para a tomada de decisão no cotidiano da formação técnica em enfermagem, bem como as lacunas do conhecimento para o desenvolvimento de futuras pesquisas.

\subsection{Análise dos dados}

Nesta são representadas as características dos estudos e suas ideias, a partir da definição das informações a serem extraídas dos documentos selecionados. Para cada documento da amostra do estudo foi preenchido um formulário de coleta de dados. Este formulário permitiu reunir informações precisas sobre cada documento e seus autores, bem como sua fonte de localização, objetivos e delineamento do estudo. A amostra foi constituída por 14 documentos sobre competências (ANEXO A).

Embora a base de dados LILACS tenha apresentado um maior número de documentos (146), ao se submeter a população identificada aos critérios de exclusão, o número de documentos selecionados para a amostra reduziu drasticamente (6). Isso ocorreu devido ao fato de que, em grande parte dos documentos, o resumo apresentado não correspondia com o que era desejado para o estudo, gerando a sua exclusão da amostra.

O IBICT forneceu a maior população para composição da amostra (8). Consideramos que por ser a maior base de dados brasileira, que reúne a maior parte das universidades brasileiras, e pela escolha da língua portuguesa como idioma, essa base de dados, embora tenha apresentado uma população menor (12), possibilitou a seleção da maior parte dessa população para compor a amostra. Em relação à qualidade das informações de pesquisas fornecidas pelo IBICT, Blattmann e Santos (2009) apontam:

A iniciativa desenvolvida pelo IBICT possibilita para consulta ou download, a produção nacional de teses e dissertações, oferece aos usuários produtos e serviços integrados capazes de proporcionar aumento significativo ao impacto e avanço de suas pesquisas.

Essa facilidade no acesso, aliada à escolha do idioma, facilita a disponibilização de estudos. 
Adão, Camargos, Pederiva e Oliveira, 2016 - Educação Profissional

\section{RESULTADOS E DISCUSSÃO}

Quadro 1. Distribuição da amostra, segundo a profissão, área de atuação e titulação do primeiro autor, São João delRei, 2014

\begin{tabular}{|c|c|c|c|}
\hline Literatura & Profissão & Área de atuação & Titulação \\
\hline $\begin{array}{l}\text { O ensino de enfermagem e as } \\
\text { diretrizes curriculares nacionais: } \\
\text { utopia } x \text { realidade. }\end{array}$ & Enfermeira & Assistência & Mestre \\
\hline $\begin{array}{l}\text { Diretrizes curriculares e } \\
\text { estratégias para implantação de } \\
\text { uma nova proposta pedagógica. }\end{array}$ & Enfermeira & Ensino & Doutora \\
\hline $\begin{array}{l}\text { Referências para o ensino de } \\
\text { competências na enfermagem. }\end{array}$ & Enfermeira & Ensino & Doutora \\
\hline $\begin{array}{l}\text { Abordagem por competências } \\
\text { no processo ensino- } \\
\text { aprendizagem. }\end{array}$ & Enfermeiro & Ensino & Doutor \\
\hline $\begin{array}{l}\text { Planejamento de ensino em } \\
\text { enfermagem: } \\
\text { educativas e as compcões } \\
\text { clínicas. }\end{array}$ & Enfermeira & Ensino & Doutora \\
\hline $\begin{array}{l}\text { Profissional crítico-criativa em } \\
\text { enfermagem: a construção do } \\
\text { espaço intercessor na relação } \\
\text { pedagógica. }\end{array}$ & Enfermeira & Ensino & Doutora \\
\hline $\begin{array}{l}\text { As competências crítico- } \\
\text { emancipatórias e a formação } \\
\text { dos trabalhadores de nível } \\
\text { médio em Enfermagem: } \\
\text { focalizando as políticas } \\
\text { ministeriais. }\end{array}$ & Enfermeira & Ensino & Mestre \\
\hline $\begin{array}{l}\text { Currículos e competências: } \\
\text { experiência docente nos cursos } \\
\text { técnicos em saúde. }\end{array}$ & Enfermeira & Ensino & Mestre \\
\hline $\begin{array}{lcr}\text { O cidadão } & \text { técnico } & \text { em } \\
\text { Enfermagem: } & \text { analisando } & \text { as } \\
\text { mudanças } & \text { na } & \text { sua }\end{array}$ & Enfermeira & Ensino & Mestre \\
\hline
\end{tabular}




\begin{tabular}{|l|l|l|l|}
\hline profissionalização. & & \\
\hline $\begin{array}{l}\text { Os sentidos da avaliação do } \\
\text { desempenho do estudante em } \\
\text { um currículo por competência. }\end{array}$ & Enfermeira & Ensino & Doutora \\
\hline $\begin{array}{l}\text { Competências gerais na área da } \\
\text { saúde: implicações na formação } \\
\text { de profissionais de enfermagem } \\
\text { de nível médio. }\end{array}$ & Enfermeira & Ensino & Mestre \\
\hline $\begin{array}{l}\text { Competências para a promoção } \\
\text { e educação em saúde em } \\
\text { estudantes de nível médio de } \\
\text { enfermagem. }\end{array}$ & Enfermeira & Ensino & Mestre \\
\hline $\begin{array}{l}\text { Ressignificando a avaliação no } \\
\text { ensino por competência em um } \\
\text { curso técnico de enfermagem. }\end{array}$ & Enfermeira & Ensino & Mestre \\
\hline $\begin{array}{l}\text { As competências na educação } \\
\text { profissional: implicações para o } \\
\text { ensino e para os saberes } \\
\text { pedagógicos dos docentes de } \\
\text { um curso técnico em } \\
\text { enfermagem. }\end{array}$ & Enfermeira & Ensino & Mestre \\
\hline
\end{tabular}

Fonte: Elaboração dos autores, 2014.

Constatamos que todos os estudos (14) tiveram enfermeiros como seus primeiros autores. Isso pode estar relacionado ao fato de que a pesquisa diz respeito à formação técnica em enfermagem, ou seja, está diretamente relacionada à área de atuação dos enfermeiros e faz parte de seu cotidiano profissional.

É importante ressaltar também que a maioria dos estudos (13) foram desenvolvidos por autores que têm sua atuação no ensino, e em apenas um estudo o primeiro autor atua na área assistencial. Relaciona-se a isso o fato de que os enfermeiros docentes estão constantemente procurando repensar a sua forma de prática educativa, propondo mudanças e buscando quebrar paradigmas. 
Outro fator importante a ser analisado é a titulação dos autores. A amostra é constituída por documentos produzidos por mestres (8) e doutores (6). Pode-se inferir a partir desse dado que possuindo um nível maior de instrução, os enfermeiros tendem a buscar formas de responder com efetividade às necessidades de mudanças na formação técnica. Essa busca acaba desembocando em uma nova proposta de modelo de ensino, no caso o modelo por competências.

No Quadro 2, as características relacionadas às publicações foram analisadas por meio das variáveis periódico, base de dados, ano de publicação e delineamento da pesquisa.

Quadro 2. Características relacionadas às publicações, São João del-Rei, 2014.

\begin{tabular}{|c|c|c|c|c|c|}
\hline Literatura & Periódico & $\begin{array}{l}\text { Fonte ou Base de } \\
\text { Dados }\end{array}$ & $\begin{array}{l}\text { Public } \\
\text { ação }\end{array}$ & $\begin{array}{l}\text { Tipo de } \\
\text { publicação }\end{array}$ & Delineamento \\
\hline $\begin{array}{l}\text { O ensino de enfermagem e } \\
\text { as diretrizes curriculares } \\
\text { nacionais: utopia } x \text { realidade }\end{array}$ & $\begin{array}{lr}\text { Rev Esc } \\
\text { Enferm USP }\end{array}$ & LILACS & 2006 & Artigo & $\begin{array}{l}\text { Pesquisa } \\
\text { bibliográfica }\end{array}$ \\
\hline $\begin{array}{lr}\text { Diretrizes curriculares } & \text { e } \\
\text { estratégias } & \text { para } \\
\text { implantação de uma nova } \\
\text { proposta pedagógica. }\end{array}$ & $\begin{array}{lr}\text { Rev Esc } \\
\text { Enferm USP }\end{array}$ & LILACS & 2005 & Artigo & $\begin{array}{l}\text { Pesquisa } \\
\text { bibliográfica }\end{array}$ \\
\hline $\begin{array}{l}\text { Referências para o ensino de } \\
\text { competências na } \\
\text { enfermagem. }\end{array}$ & $\begin{array}{l}\text { Rev Bras } \\
\text { Enferm }\end{array}$ & LILACS & 2005 & Artigo & $\begin{array}{l}\text { Pesquisa } \\
\text { bibliográfica }\end{array}$ \\
\hline $\begin{array}{l}\text { Abordagem por } \\
\text { competências no processo } \\
\text { ensino-aprendizagem. }\end{array}$ & $\begin{array}{l}\text { Rev Bras } \\
\text { Enferm }\end{array}$ & LILACS & 2005 & Artigo & Estudo de caso \\
\hline $\begin{array}{l}\text { Planejamento de ensino em } \\
\text { enfermagem: intenções } \\
\text { educativas e as } \\
\text { competências clínicas. }\end{array}$ & $\begin{array}{lr}\text { Rev Esc } \\
\text { Enferm USP }\end{array}$ & LILACS & 2009 & Artigo & $\begin{array}{l}\text { Pesquisa } \\
\text { bibliográfica }\end{array}$ \\
\hline $\begin{array}{l}\text { Profissional crítico-criativa } \\
\text { em enfermagem: a } \\
\text { construção do espaço } \\
\text { interseçor na relação } \\
\text { pedagógica. }\end{array}$ & $\begin{array}{l}\text { Rev Bras } \\
\text { Enferm }\end{array}$ & LILACS & 2004 & Artigo & Estudo de caso \\
\hline As competências crítico- & Não & Biblioteca & 2007 & Dissertação & Pesquisa \\
\hline
\end{tabular}


Adão, Camargos, Pederiva e Oliveira, 2016 - Educação Profissional

\begin{tabular}{|c|c|c|c|c|c|}
\hline $\begin{array}{l}\text { emancipatórias e a } \\
\text { formação dos trabalhadores } \\
\text { de nível médio em } \\
\text { Enfermagem: focalizando as } \\
\text { políticas ministeriais. }\end{array}$ & aplica & $\begin{array}{l}\text { Universidade de } \\
\text { São Paulo }\end{array}$ & & & documental \\
\hline $\begin{array}{l}\text { Currículos e competências: } \\
\text { experiência docente nos } \\
\text { cursos técnicos em saúde. }\end{array}$ & $\begin{array}{ll}\text { Não } & \text { se } \\
\text { aplica } & \end{array}$ & $\begin{array}{l}\text { Biblioteca da } \\
\text { Universidade } \\
\text { Federal da Bahia }\end{array}$ & 2010 & Dissertação & Estudo de caso \\
\hline $\begin{array}{l}\text { O cidadão técnico em } \\
\text { Enfermagem: analisando as } \\
\text { mudanças na sua } \\
\text { profissionalização. }\end{array}$ & $\begin{array}{ll}\text { Não } & \text { se } \\
\text { aplica } & \end{array}$ & $\begin{array}{l}\text { Biblioteca da } \\
\text { Universidade } \\
\text { Federal do Rio } \\
\text { Grande do Norte }\end{array}$ & 2003 & Dissertação & Pesquisa-ação \\
\hline $\begin{array}{l}\text { Os sentidos da avaliação do } \\
\text { desempenho do estudante } \\
\text { em um currículo por } \\
\text { competência. }\end{array}$ & $\begin{array}{ll}\text { Não } & \text { se } \\
\text { aplica } & \end{array}$ & $\begin{array}{ll}\text { Biblioteca } & \text { da } \\
\text { Universidade } & \text { de } \\
\text { São Paulo } & \end{array}$ & 2009 & Tese & Estudo de caso \\
\hline $\begin{array}{l}\text { Competências gerais na área } \\
\text { da saúde: implicações na } \\
\text { formação de profissionais de } \\
\text { enfermagem de nível médio. }\end{array}$ & $\begin{array}{l}\text { Não } \\
\text { aplica }\end{array}$ & $\begin{array}{ll}\text { Biblioteca } & \text { da } \\
\text { Universidade } & \text { de } \\
\text { São Paulo } & \end{array}$ & 2008 & Dissertação & $\begin{array}{l}\text { Pesquisa } \\
\text { documental }\end{array}$ \\
\hline $\begin{array}{l}\text { Competências para a } \\
\text { promoção e educação em } \\
\text { saúde em estudantes de } \\
\text { nível médio de enfermagem. }\end{array}$ & $\begin{array}{ll}\text { Não } & \text { se } \\
\text { aplica } & \end{array}$ & $\begin{array}{ll}\text { Biblioteca } & \text { da } \\
\text { Universidade } & \text { do } \\
\text { Vale do Itajaí } & \end{array}$ & 2006 & Dissertação & Estudo de caso \\
\hline $\begin{array}{l}\text { Ressignificando a avaliação } \\
\text { no ensino por competência } \\
\text { em um curso técnico de } \\
\text { enfermagem. }\end{array}$ & $\begin{array}{ll}\text { Não } & \text { se } \\
\text { aplica } & \end{array}$ & $\begin{array}{l}\text { Biblioteca da } \\
\text { Universidade } \\
\text { Federal de Santa } \\
\text { Catarina }\end{array}$ & 2007 & Dissertação & Estudo de caso \\
\hline $\begin{array}{l}\text { As competências na } \\
\text { educação profissional: } \\
\text { implicações para o ensino e } \\
\text { para os saberes pedagógicos } \\
\text { dos docentes de um curso } \\
\text { técnico em enfermagem. }\end{array}$ & $\begin{array}{ll}\text { Não } & \text { se } \\
\text { aplica } & \end{array}$ & $\begin{array}{lr}\text { Biblioteca } & \text { da } \\
\text { Universidade } & \\
\text { Católica } & \text { Dom } \\
\text { Bosco } & \end{array}$ & 2006 & Dissertação & Estudo de caso \\
\hline
\end{tabular}

Fonte: Elaboração dos autores, 2014. 
Em relação à primeira variável estudada, observa-se que os artigos foram encontrados em apenas dois periódicos: Revista da Escola de Enfermagem da USP e Revista Brasileira de Enfermagem. A Revista Brasileira de Enfermagem é uma publicação da Associação Brasileira de Enfermagem (ABEN), entidade representativa da Enfermagem, que tem como uma de suas finalidades: “(...) promover o desenvolvimento técnico, científico e profissional dos integrantes de Enfermagem do País, pautado em princípios éticos" (ABEN, 2005) sendo, portanto, comprometida com as discussões que permeiam o desenvolvimento técnico da Enfermagem. A Revista da Escola de Enfermagem da USP está vinculada a um polo de pesquisa da Enfermagem e compromete-se com a produção e difusão de conhecimento, por meio de pesquisas científicas acerca de temas relevantes para a área, daí é possível entender o fato de ter aparecido várias vezes na pesquisa.

$\mathrm{Na}$ amostra estudada, a maioria dos documentos (8) foi encontrada em bibliotecas de universidades e apenas seis na base LILACS. Entende-se que o uso da base de dados IBICT facilitou a busca nas bibliotecas das universidades, ao reunir grande parte destas em um só local de busca.

Quanto ao ano de publicação, foram encontrados um documento de 2003, um documento de 2004, três documentos de 2005, três documentos de 2006, dois documentos de 2007, um documento de 2008, dois documentos de 2009 e um documento de 2010.

$\mathrm{Na}$ análise da variável tipo de publicação encontramos os seguintes resultados: seis artigos, sete dissertações e uma tese. A partir disso pode ser observado que o tema de modelo por competências tem chamado a atenção da comunidade acadêmica, que vem produzindo estudos na área e propondo novas práticas pedagógicas, com o intuito de elevar o nível da Enfermagem como um todo e dar voz à sociedade no que diz respeito aos anseios por uma assistência de qualidade e livre de riscos.

Analisando os delineamentos das pesquisas, constata-se que a maioria (7) utilizou estudos de caso. Esta observação é muito importante, já que permite inferir que os autores, ao se depararem com um problema em sua realidade, procuraram estudá-lo e buscar novas respostas e novas indagações no desenvolvimento do seu trabalho.

No Quadro 3, apresentam-se os desafios apontados pelos autores em relação à transposição do modelo de ensino tradicional pelo modelo por competências. 
Adão, Camargos, Pederiva e Oliveira, 2016 - Educação Profissional

Quadro 3. Desafios apontados pelos autores na transposição do modelo tradicional pelo modelo por competências,

São João del-Rei, 2014.

\begin{tabular}{|c|c|}
\hline Literatura & $\begin{array}{l}\text { Desafios apontados pelos autores na transposição do modelo } \\
\text { tradicional pelo modelo por competências }\end{array}$ \\
\hline $\begin{array}{l}\text { O ensino de enfermagem e as } \\
\text { diretrizes curriculares nacionais: } \\
\text { utopia } x \text { realidade }\end{array}$ & $\begin{array}{l}\text { Adoção de referencial teórico-pedagógico que sustente uma } \\
\text { aprendizagem significativa, transformadora e adequada às demandas } \\
\text { sociais e profissionais que se apresentam. }\end{array}$ \\
\hline $\begin{array}{l}\text { Diretrizes curriculares e } \\
\text { estratégias para implantação de } \\
\text { uma nova proposta pedagógica. }\end{array}$ & $\begin{array}{l}\text { Aponta obstáculos que classifica como relativos: o envolvimento do } \\
\text { grupo no projeto de mudança, a peculiaridade do trabalho coletivo, as } \\
\text { especificidades da prática, a possibilidade de resistência do grupo } \\
\text { docente e o entendimento da necessidade de transformação. }\end{array}$ \\
\hline $\begin{array}{l}\text { Referências para o ensino de } \\
\text { competências na enfermagem. }\end{array}$ & $\begin{array}{l}\text { Construção de competências inerentes à carreira docente para que a } \\
\text { construção de um profissional competente não permaneça como um } \\
\text { desejo, uma necessidade percebida e verbalizada, porém sem } \\
\text { expressões de efetividade. }\end{array}$ \\
\hline $\begin{array}{l}\text { Abordagem por competências } \\
\text { no processo ensino- } \\
\text { aprendizagem. }\end{array}$ & $\begin{array}{l}\text { Salienta que assumir que o ensino por competências é apenas a ponta } \\
\text { mais visível de uma mudança radical de conceitos, significa dizer que } \\
\text { romper com os antigos paradigmas é condição existencial para essa } \\
\text { abordagem. }\end{array}$ \\
\hline $\begin{array}{l}\text { Planejamento de ensino em } \\
\text { enfermagem: intenções } \\
\text { educativas e as competências } \\
\text { clínicas. }\end{array}$ & $\begin{array}{l}\text { Necessidade de superar a visão tecnicista da educação profissional, de } \\
\text { possibilitar maior autonomia aos trabalhadores para tomar decisões e } \\
\text { gerenciar sua vida profissional e de propiciar condições para que eles } \\
\text { possam assumir responsabilidade frente a situações de trabalho } \\
\text { complexas. }\end{array}$ \\
\hline $\begin{array}{l}\text { Profissional crítico-criativo em } \\
\text { enfermagem: a construção do } \\
\text { espaço intercessor na relação } \\
\text { pedagógica. }\end{array}$ & $\begin{array}{l}\text { Necessidade de mobilizar certas atitudes por parte do professor, em } \\
\text { que a sensibilidade e a emoção sejam instrumentos para ativar outras } \\
\text { formas de pensar, investigar e assistir. }\end{array}$ \\
\hline $\begin{array}{l}\text { As competências crítico- } \\
\text { emancipatórias e a formação } \\
\text { dos trabalhadores de nível } \\
\text { médio em Enfermagem: } \\
\text { focalizando as políticas } \\
\text { ministeriais. }\end{array}$ & $\begin{array}{l}\text { Mudanças nas estratégias pedagógicas, com redefinição do papel dos } \\
\text { docentes e dos discentes, e mudanças na organização dos processos de } \\
\text { trabalho e nas instituições, sendo necessária a articulação ao trabalho. }\end{array}$ \\
\hline $\begin{array}{l}\text { Currículos e competências: } \\
\text { experiência docente nos cursos }\end{array}$ & $\begin{array}{l}\text { Ampliação dos elementos contextuais, considerando a complexidade do } \\
\text { processo de trabalho em saúde e a inclusão do usuário como sujeito e } \\
\text { não como objeto das práticas de saúde. Ressalta como dificuldade a }\end{array}$ \\
\hline
\end{tabular}




\begin{tabular}{|c|c|}
\hline técnicos em saúde. & $\begin{array}{l}\text { fragilidade da formação docente que carece de uma visão crítico- } \\
\text { reflexiva que reconheça a necessidade de mudança do modelo de } \\
\text { ensino. }\end{array}$ \\
\hline $\begin{array}{lcr}\text { O cidadão } & \text { técnico } & \text { em } \\
\text { Enfermagem: analisando } & \text { as } \\
\text { mudanças } & \text { na } & \text { sua } \\
\text { profissionalização. }\end{array}$ & $\begin{array}{l}\text { Uso de metodologias inovadoras de ensino, nas quais o educando é } \\
\text { sujeito ativo do processo ensino-aprendizagem, com participação } \\
\text { efetiva em seminários, pesquisas, estudos em grupos, debates e trocas } \\
\text { de experiências. }\end{array}$ \\
\hline $\begin{array}{l}\text { Os sentidos da avaliação do } \\
\text { desempenho do estudante em } \\
\text { um currículo por competência. }\end{array}$ & $\begin{array}{l}\text { Aceitação dos docentes e alunos de uma nova forma de avaliação que } \\
\text { reflita mudanças efetivas na prática pedagógica. }\end{array}$ \\
\hline $\begin{array}{l}\text { Competências gerais na área da } \\
\text { saúde: implicações na formação } \\
\text { de profissionais de enfermagem } \\
\text { de nível médio. }\end{array}$ & $\begin{array}{l}\text { Mudança na concepção de educação, passando a entendendê-la como } \\
\text { uma ação voltada para a formação de sujeitos sociais, capazes e } \\
\text { interessados em cuidar para que o futuro seja melhor que o presente. }\end{array}$ \\
\hline $\begin{array}{l}\text { Competências para a promoção } \\
\text { e educação em saúde em } \\
\text { estudantes de nível médio de } \\
\text { enfermagem. }\end{array}$ & $\begin{array}{l}\text { Superação do modelo biomédico vigente na formação dos técnicos em } \\
\text { enfermagem, orientando a formação centrada em um modelo que } \\
\text { priorize o atendimento das necessidades de saúde da população por } \\
\text { meio de uma abordagem interdisciplinar. }\end{array}$ \\
\hline $\begin{array}{l}\text { Ressignificando a avaliação no } \\
\text { ensino por competência em um } \\
\text { curso técnico de enfermagem. }\end{array}$ & $\begin{array}{l}\text { Mudança de postura dos docentes, que permita avaliarem suas práticas } \\
\text { pedagógicas e estarem abertos a novas formas de ensinar, o que } \\
\text { resultaria também na necessidade de uma nova forma de avaliar. }\end{array}$ \\
\hline $\begin{array}{l}\text { As competências na educação } \\
\text { profissional: implicações para o } \\
\text { ensino e para os saberes } \\
\text { pedagógicos dos docentes de } \\
\text { um curso técnico em } \\
\text { enfermagem. }\end{array}$ & Formação continuada dos docentes é prioridade nesse processo. \\
\hline
\end{tabular}

Fonte: Elaboração dos autores, 2014.

Observando os desafios apontados pelos autores, nota-se que a maioria (4) aponta para a necessidade de mudanças, seja na postura dos docentes, nas práticas pedagógicas ou na própria concepção de educação. A mudança, apontada como um dos desafios para a implementação do modelo por competências, pode surgir a partir de uma análise da forma como é construído o conhecimento no modelo tradicional. Neste, o conhecimento é fragmentado, não são estabelecidas relações com a realidade, e as metodologias utilizadas, tais como a memorização, não promovem a aprendizagem de maneira eficaz, além de serem na maioria das vezes 
desestimulantes. Ademais, a ênfase dada às situações de sala de aula, onde os alunos são "instruídos" ao invés de "ensinados", contribui para a formação de reações estereotipadas e automatismos. Por conseguinte, ao se depararem com situações que exijam flexibilidade e inovação, os educandos encontram dificuldades de enfrentamento e criação de soluções, já que interiorizaram comportamentos automáticos que apenas correspondem a situações idênticas às quais foram "treinados" a lidar.

Oliveira (2006) aponta que o modelo tradicional de ensino não atende às novas necessidades da sociedade, que carece de profissionais aptos a identificar e tratar os problemas e princípios organizadores que permitam ligar os saberes. No tocante aos desafios citados, muitas pesquisas (6) apontam a figura do docente, salientando a resistência quanto à adoção de novas formas de ensinar, a fragilidade na formação, a dificuldade na mudança dos paradigmas e a necessidade de formação continuada. Essa predominância da figura do docente é justificada pelo papel que assume na mudança do modelo de ensino, o que é apontado por Bowen e Hobson (1987): "Os professores estão envolvidos num papel central em tudo isto, pois é sobre eles que recai a tarefa de pôr em prática qualquer forma de educação que procuremos desenvolver." Assim, é natural que grande parte dos autores ressaltem a responsabilidade do docente nos novos modelos de ensino, pois sem a colaboração, entendimento e cooperação por parte dos mesmos, nenhuma mudança será implementada com sucesso.

\section{CONSIDERAÇÕES FINAIS}

Neste estudo, foi realizada uma pesquisa de revisão integrativa de literatura da produção científica nacional, do período compreendido entre 2001 e 2011, sobre a transposição do modelo de ensino tradicional pelo modelo por competências. O trabalho apontou que na aprendizagem de uma profissão está presente uma complexidade, e os saberes dissociados e descontextualizados, inerentes ao ensino tradicional, contribuem para a visão fragmentada e dissociada da realidade. Diversos autores propõem o modelo por competências como o ideal para o ensino profissional. Por meio da análise dos resultados obtidos, foi possível observar que o tema tem despertado grande interesse na comunidade acadêmica, que vem produzindo vários estudos nesse sentido. Embora a universidade seja um difusor de conhecimentos, faz-se necessário que essa preocupação seja também compartilhada por outros setores da Enfermagem. É importante, por exemplo, que haja um maior envolvimento do setor assistencial, uma vez que o profissional formado atuará 
diretamente nesse setor e sua formação trará implicações diretas para a sua prática profissional. Mas fica a questão: de que forma esse setor poderia colaborar com estudos a fim fornecer contribuições a essa discussão?

Embora sempre se reafirme a importância da participação dos diversos níveis de atuação da Enfermagem na discussão acerca dos perfis de formação dos profissionais, observa-se haver uma lacuna importante na produção científica no meio assistencial. A que se deve isso? Se essa lacuna não for preenchida, é possível que nenhuma mudança seja significativa, uma vez que não haverá mudanças reais na prática assistencial. Do ponto de vista assistencial, essas mudanças propostas estão condizentes com a realidade vivenciada por esses profissionais? Por diversas vezes foi apontada a figura do docente, aqui representado pelo enfermeiro vinculado ao ensino, como uma das peças fundamentais para a mudança do modelo de ensino. No entanto, é importante que não se esqueça que todo enfermeiro é um educador em sua essência e, portanto, um importante colaborador em potencial que precisa ser melhor explorado. Ressalta-se, ainda, a necessidade de que novos estudos sejam realizados e que esta pesquisa seja replicada com a utilização de outros descritores.

Por fim, é necessário deixar claro que este estudo não pretende esgotar a discussão sobre o tema, nem sequer indicar caminhos a serem percorridos para que as transformações necessárias sejam alcançadas. Ele apenas sugere a superação das abordagens tradicionais e a necessidade de mudar paradigmas, fazer rupturas com práticas e crenças que nos impedem de fazer mudanças e enfrentar desafios. Trata-se, portanto, de uma contribuição ao debate coletivo e crítico para a construção do projeto de uma Enfermagem mais humana, crítica e ética.

\section{REFERÊNCIAS}

ALMEIDA FILHO, N. Transdisciplinaridade e Saúde Coletiva. Ciência \& Saúde Coletiva. II (1-2), 1997.

ASSOCIAÇÃO BRASILEIRA DE ENFERMAGEM. Estatuto da ABEn. Goiânia, Goiás, 2005.

BALDI, Miriã Dias Bibow. Competências para a promoção e educação em saúde em estudantes de nível médio em enfermagem.. 2006, 120p. Dissertação (Mestrado Profissionalizante em Saúde e Gestão do Trabalho), Universidade do Vale do Itajaí, Itajaí, 2006.

BRACCIALLI, Luzmarina Aparecida Doretto. Os sentidos da avaliação do desempenho do estudante em um currículo por competência. 2009, 280p. Tese (Doutorado em Enfermagem), Universidade de São Paulo, São Paulo, 2009. 
BRASIL. [Lei Darcy Ribeiro (1996)]. LDB : Lei de Diretrizes e Bases da Educação Nacional : lei no 9.394 , de 20 de dezembro de 1996, que estabelece as diretrizes e bases da educação nacional. - 5. ed. - Brasília : Câmara dos Deputados, Coordenação Edições Câmara, 2010.

BLATTMANN, Ursula; SANTOS, Raimundo Nonato Macedo dos. Acesso e uso de tecnologias em teses de dissertações: o caso BDTD. In: CONGRESSO DA ASSOCIATION INTERNATIONALE POUR LA RECHERCE INTERCULTURALLE, 12. 2009, Anais eletrônicos... Florianópolis : $2009 . \quad$ Disponível em: <http://aric.edugraf.ufsc.br/congrio/anais/artigo/201/textoCompleto>. Acesso em: 8 jan. 2015.

BOWEN, James; HOBSON, Peter. Theories of Education: Studies of Significant Innovatios in Western Educational Thought. Brisbane: John Wiley \& Sons, 1987, 2. ed., pp. 8-9.

BRASIL. Ministério da Educação e do Desporto. Diretrizes Curriculares - Nível tecnológico. Parecer CNE/CP 29, de 03/12/2002. Disponível em: <http:www.mec.gov.br/setec/arquivos/pdf/legisla05>. Acesso em: 22 setembro 2015.

CAMARÃO, Maria José Cortês. Currículos e competências: experiência docente nos cursos técnicos em saúde. 2010, 76p. Dissertação (Mestrado em Saúde Coletiva), Universidade Federal da Bahia, Salvador, 2010.

CONSELHO ESTADUAL DE EDUCAÇÃO (CEE). Indicação CEE no. 8/2000. São Paulo, 2000. Disponível em: <http://www.crmariocovas.sp.gov.br/pdf/diretrizes_p0987-1002_c.pdf>. Acesso em 08 Jan. 2015.

DE DOMENICO, Edvane Birelo Lopes; IDE, Cilene Aparecida Costardi. Referências para o ensino de competências na enfermagem. Rev Bras Enferm; 58(4): 453-457, jul.-ago. 2005.

DELL'ACQUA, Magda Cristina Queiroz; MIYADAHIRA, Ana Maria Kazue; IDE, Cilene Aparecida Costardi. Planejamento de ensino em enfermagem: intenções educativas e as competências clínicas. Rev Esc Enferm USP; 43(2) jun. 2009.

FARIAS, M. F. SONAGLIO, K. E. Perspectivas multi, pluri, inter e transdisciplinar no turismo. Revista Iberoamericana de Turismo- RITUR, Penedo, A vol. 3, n.1, p. 79, 2013. Disponível em: <http://www.seer.ufal.br/index.php/ritur>. Acesso em 18 de jun. 2016.

FERNANDES, Josicélia Dumêt et al. Diretrizes curriculares e estratégias para implantação de uma nova proposta pedagógica. Rev Esc Enferm USP; 39(4): 443-449, dez. 2005.

FREIRE, Paulo. Pedagogia do Oprimido. Rio de Janeiro: Paz e Terra, 1987.

Pedagogia da autonomia: saberes necessários à prática educativa. 30ạ edição. São Paulo: Paz e Terra, 2004.

ITO, Elaine Emi et al. O ensino de enfermagem e as diretrizes curriculares nacionais: utopia $\mathrm{x}$ realidade. Rev Esc Enferm USP; 40(4): 570-575, dez. 2006.

LINDER, Maria Estela Freire da Palma. Competências gerais na área da saúde: implicações na formação de profissionais de enfermagem de nível médio. 2008, 168p. Dissertação (Mestrado em Enfermagem), Universidade de São Paulo, Ribeirão Preto, 2008.

LOPES, Alice Casimiro. Parâmetros Curriculares para o ensino médio: quando a integração perder seu potencia crítico. In: LOPES, A.C; MACEDO, E.F. (Org.). Disciplinas e integração curricular: história e políticas. Rio de Janeiro: DP\&A, 2002.

MARQUES, Claúdia Maria da Silva. As competências crítico-emancipatórias e a formação dos trabalhadores de nível médio em Enfermagem: focalizando as políticas ministeriais. 2007. 91p. Dissertação (Mestrado em Enfermagem), Universidade de São Paulo, São Paulo, 2007.

MELLO, Guiomar Namo de. Cidadania e competitividade - desafios educacionais do 3o milênio. São Paulo: Cortez, 1993. 
MORIN, Edgard. Os sete saberes necessários à educação do futuro. 3a. ed. - São Paulo: Cortez; Brasília, DF: UNESCO, 2001

NIQUINI, Débora Pinto. A transposição didática e o contrato didático. Brasília: Petry, 1999.

OLIVEIRA, Cacilda Lages. Significado e contribuições da afetividade no contexto da Metodologia de Projetos na Educação Básica. Dissertação (Mestrado em Educação), CEFET-MG, Belo Horizonte, Minas Gerais, 2006.

PEREIRA, Lucia Helena Pena. Bioexpressão: a caminho de uma educação lúdica para educadores. 2005. 403p. Tese (Doutorado em Educação), Universidade Federal da Bahia, Salvador, Bahia, 2005.

PERRENOUD, Philippe. et al. As competências para ensinar no século XXI: a formação dos professores e o desafio da avaliação. Porto Alegre: Artmed, 2002.

PRADO, Rosane Aparecida do. As competências na educação profissional: implicações para o ensino e para os saberes pedagógicos dos docentes de um curso técnico em enfermagem. 2007, 106p. Dissertação (Mestrado em Enfermagem), Universidade Federal de Santa Catarina, Florianópolis, 2007.

RAMOS, Marise Nogueira. A Pedagogia das competências: autonomia ou adaptação? São Paulo: Cortez, 2001.

REHEM, Cleunice Matos. Estudo sobre o perfil do professor da Educação Técnica e contribuições para um projeto contemporâneo de formação docente no Brasil, numa perspectiva do trabalho e da educação no início do século XXI. Dissertação (Mestrado em Educação). Universidade Federal Rural do Rio de Janeiro, 2005, 176 p.

REIBNITZ, Kenya Schmidt. Profissional crítico-criativa em enfermagem: a construção do espaço interseçor na relação pedagógica. Rev Bras Enferm; 57(6): 698-702, nov.-dez. 2004.

RICARDO, Elio Carlos. Discussão acerca do ensino por competências: problemas e alternativas. Cadernos de Pesquisa, v.40, n.140, p. 605-628, maio/ago. 2010.

SILVA, César Cavalcanti da. Abordagem por competências no processo ensino- aprendizagem. Rev Bras Enferm; 58(1): 91-94, jan.-fev. 2005.

SILVA, Edilene Rodrigues da. $\mathbf{O}$ cidadão técnico em Enfermagem: analisando as mudanças na sua profissionalização. 2003, 91p. Dissertação (Mestrado em Enfermagem), Universidade Federal do Rio Grande do Norte, Natal, 2003.

SOUZA, Marcela Tavares; SILVA, Michelly Dias da; CARVALHO, Rachel. Revisão Integrativa: o que é como fazer. Einstein. 2010; 8 (1 Pt 1):102-6.

SOUZA, Rosilaine Moreira de. Ressignificando a avaliação no ensino por competência em um curso técnico de enfermagem. 2006, 120p. Dissertação (Mestrado Profissionalizante em Saúde e Gestão do Trabalho), Universidade do Vale do Itajaí, Itajaí, 2006.

STROOBANTS, Marcele. A visibilidade das competências. In ROPÉ, Françoise, TANGUY, Lucie (org.). Saberes e competências: o uso de tais noções na escola e na empresa. Campinas: Papirus, 1997. p.135-166.

VAZ, Marcelo Caetano. A formação e o desenvolvimento de competências dos tecnólogos no mundo do trabalho. 2009. 113p. Tese (Doutorado em Educação), Pontifícia Universidade Católica, São Paulo, 2009.

VIDAL, Elisabete. Ensino à distância vs Ensino tradicional. 2002. 76p. Dissertação (Mestrado em Educação), Universidade Fernando Pessoa, Porto, 2002.

WITTACZIK, Lidiane Soares. Ensino por competências: possibilidades e limitações. ATOS DE PESQUISA EM EDUCAÇÃO - PPGE/ME FURB. v. 2, no 1, p. 161-172, jan./abr. 2007.

ZARIFIAN, Philippe. Objetivo competência: por uma nova lógica. São Paulo: Atlas, 2001. 


\section{ANEXO A \\ DOCUMENTOS QUE COMPÕEM A AMOSTRA DA PESQUISA}

BALDI, Miriã Dias Bibow. Competências para a promoção e educação em saúde em estudantes de nível médio em enfermagem.. 2006, 120p. Dissertação (Mestrado Profissionalizante em Saúde e Gestão do Trabalho), Universidade do Vale do Itajaí, Itajaí, 2006.

BRACCIALLI, Luzmarina Aparecida Doretto. Os sentidos da avaliação do desempenho do estudante em um currículo por competência. 2009, 280p. Tese (Doutorado em Enfermagem), Universidade de São Paulo, São Paulo, 2009.

CAMARÃO, Maria José Cortês. Currículos e competências: experiência docente nos cursos técnicos em saúde. 2010, 76p. Dissertação (Mestrado em Saúde Coletiva), Universidade Federal da Bahia, Salvador, 2010.

DE DOMENICO, Edvane Birelo Lopes; IDE, Cilene Aparecida Costardi. Referências para o ensino de competências na enfermagem. Rev Bras Enferm; 58(4): 453-457, jul.-ago. 2005.

DELL'ACQUA, Magda Cristina Queiroz; MIYADAHIRA, Ana Maria Kazue; IDE, Cilene Aparecida Costardi. Planejamento de ensino em enfermagem: intenções educativas e as competências clínicas. Rev Esc Enferm USP; 43(2) jun. 2009.

FERNANDES, Josicélia Dumêt et al. Diretrizes curriculares e estratégias para implantação de uma nova proposta pedagógica. Rev Esc Enferm USP; 39(4): 443-449, dez. 2005.

ITO, Elaine Emi et al. O ensino de enfermagem e as diretrizes curriculares nacionais: utopia $\mathrm{x}$ realidade. Rev Esc Enferm USP; 40(4): 570-575, dez. 2006.

LINDER, Maria Estela Freire da Palma. Competências gerais na área da saúde: implicações na formação de profissionais de enfermagem de nível médio. 2008, 168p. Dissertação (Mestrado em Enfermagem), Universidade de São Paulo, Ribeirão Preto, 2008.

MARQUES, Claúdia Maria da Silva. As competências crítico-emancipatórias e a formação dos trabalhadores de nível médio em Enfermagem: focalizando as políticas ministeriais. 2007. 91p. Dissertação (Mestrado em Enfermagem), Universidade de São Paulo, São Paulo, 2007.

PRADO, Rosane Aparecida do. As competências na educação profissional: implicações para o ensino e para os saberes pedagógicos dos docentes de um curso técnico em enfermagem. 2007, 106p. Dissertação (Mestrado em Enfermagem), Universidade Católica Dom Bosco, Campo Grande, 2006.

REIBNITZ, Kenya Schmidt. Profissional crítico-criativo em enfermagem: a construção do espaço interseçor na relação pedagógica. Rev Bras Enferm; 57(6): 698-702, nov.-dez. 2004.

SILVA, César Cavalcanti da. Abordagem por competências no processo ensino- aprendizagem. Rev Bras Enferm; 58(1): 91-94, jan.-fev. 2005.

SILVA, Edilene Rodrigues da. $\mathbf{O}$ cidadão técnico em Enfermagem: analisando as mudanças na sua profissionalização. 2003, 91p. Dissertação (Mestrado em Enfermagem), Universidade Federal do Rio Grande do Norte, Natal, 2003.

SOUZA, Rosilaine Moreira de. Ressignificando a avaliação no ensino por competência em um curso técnico de enfermagem. 2006, 120p. Dissertação (Mestrado Profissionalizante em Saúde e Gestão do Trabalho), Universidade do Vale do Itajaí, Itajaí, 2006. 